\title{
Understanding and Preventing Sudden Death: Your Life Matters
}

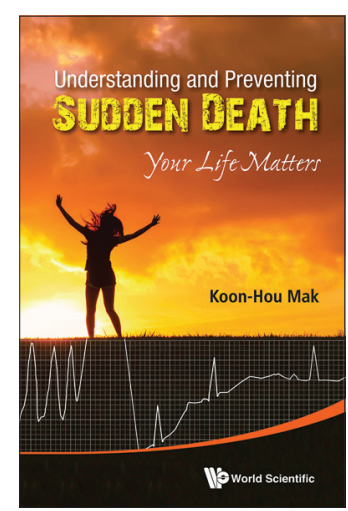

Author Koon-Hou Mak

Publisher World Scientific Publishing Co Pte Ltd, Singapore

Published 2015

Pages 339, Paperback

ISBN 9789814641159

Retail price USD 28

Dr Mak Koon-Hou has made a brave and ambitious attempt to bridge the chasm between a medical book and a book that the 'man on the MRT' can understand. Understanding and Preventing Sudden Death: Your Life Matters is the result of this endeavour - the 339-page book is ostensibly targeted at the layperson. Dr Mak is a locally and internationally renowned cardiologist who also authored the book Your Heart Matters, which is now in its second edition. In this latest book, he does not sensationalise the issue at hand but offers statements of facts that are backed by peer-reviewed references, which take up about one-fifth of the book.

The book is divided into three unequal parts. Part I comprises a foreword by several illustrious colleagues, a preface by Emeritus Senior Minister Goh Chok Tong and a short introductory chapter. Part II is a collection of ten stories centred around a diagnostic theme; for example, there are chapters each dedicated to 'hypertrophic cardiomyopathy' and 'long QT syndrome'. Part III consists of a compilation of preventive measures, including lifestyle changes and medical interventions, that may or may not prevent sudden death.

The anthology format of the book serves it well, as it allows a reader to choose the chapter that is of interest. In the chapter 'It's Not Only the Heart', Dr Mak starts off with the little known story of Sir Stamford Raffles' death from cerebral haemorrhage at his home in England. This is the common thread of all the short chapters in Part II. The anecdotes that preface each chapter succeed in introducing the reader to the chapter's content and also make the material accessible to non-medical readers by providing an interesting story leading into the medical content.

This format cannot be fully replicated for Part III because prevention only works if 'nothing happens', and there is no story to tell if 'nothing happens'. Instead, Dr Mak has chosen to illustrate the content with interesting accounts (once again, all nicely referenced) of the origin of treatments or devices and the struggle for them to gain acceptance.

However, gaps remain for the pedantic historian. For example, in the chapter 'Empowering the Rescuer', which talks about defibrillation by first responders, there are omissions of the important contributions of Frank Pantridge, John Geddes and the oftforgotten engineer, Alfred Mawhinney, in the development of the first portable cardiac defibrillator. Another omission is found in the chapter 'Poisons and Medicines'; although Akira Endo was rightfully credited for the discovery of HMG CoA inhibitors (more commonly known as 'statins'), the background story of how his employers at Daiichi Sankyo failed to recognise the commercial significance of the patent was not explored.

All in all, this book successfully covers the most common maladies that may cause one's untimely appointment with the Grim Reaper, as well as the potential ways one can successfully defer this appointment. The content is unavoidably heavy and would be suitable reading for a fairly well-educated, non-medical person. Medical students and doctors-in-training will also find this book interesting. Rest assured, the information is accurate and evidence-based. Even a specialist will find interesting nuggets of information, such as the development of our understanding of each disease and treatment, which are often missing from lectures, medical journals and books. This approach brings a refreshing depth and breadth to the subject matter. After all, one must know the past in order to understand the present and to shape the future. Dr Mak's book does that in spades.

Dr Ong Hean Yee, MBBCh BAO, FRCP

Senior Consultant and Head of Department, Department of Cardiology, Khoo Teck Puat Hospital, Singapore 